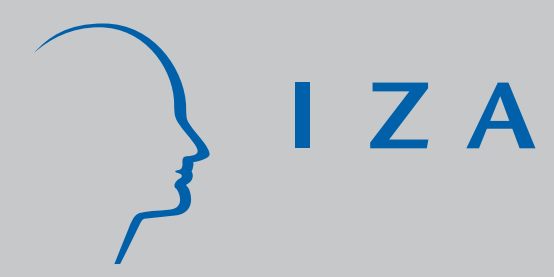

IZADP No. 1616

Nonparametric Bounds on the Effect of Deductibles in Health Care Insurance on Doctor Visits - Swiss Evidence

Michael Gerfin

Martin Schellhorn

May 2005 


\title{
Nonparametric Bounds on the Effect of Deductibles in Health Care Insurance on Doctor Visits - Swiss Evidence
}

\author{
Michael Gerfin \\ University of Bern \\ and IZA Bonn \\ Martin Schellhorn \\ GSF, Institute of Health Economics and Health Care Management, Munich, \\ University of Bern and IZA Bonn
}

Discussion Paper No. 1616

May 2005

IZA

P.O. Box 7240

53072 Bonn

Germany

Phone: +49-228-3894-0

Fax: +49-228-3894-180

Email: iza@iza.org

Any opinions expressed here are those of the author(s) and not those of the institute. Research disseminated by IZA may include views on policy, but the institute itself takes no institutional policy positions.

The Institute for the Study of Labor (IZA) in Bonn is a local and virtual international research center and a place of communication between science, politics and business. IZA is an independent nonprofit company supported by Deutsche Post World Net. The center is associated with the University of Bonn and offers a stimulating research environment through its research networks, research support, and visitors and doctoral programs. IZA engages in (i) original and internationally competitive research in all fields of labor economics, (ii) development of policy concepts, and (iii) dissemination of research results and concepts to the interested public.

IZA Discussion Papers often represent preliminary work and are circulated to encourage discussion. Citation of such a paper should account for its provisional character. A revised version may be available directly from the author. 


\section{ABSTRACT}

\section{Nonparametric Bounds on the Effect of Deductibles in Health Care Insurance on Doctor Visits - Swiss Evidence*}

We evaluate the effect of the size of deductibles in the basic health insurance in Switzerland on the probability of a doctor visit. We employ nonparametric bounding techniques to minimise statistical assumptions. In order to tighten the bounds we consider three further assumptions: mean independence of an instrument, monotone treatment response, and monotone treatment selection. Under the first two assumptions we are able to bound the treatment effect of high deductibles compared to low deductibles below zero. Adding the third assumption allows to tighten the bounds further. We conclude that there is a negative treatment effect.

JEL Classification: $\quad \mathrm{C} 14, \mathrm{I} 19$

Keywords: treatment effects, bounds, health insurance

Corresponding author:

Michael Gerfin

Department of Economics

Universität Bern

Gesellschaftsstr. 49

$\mathrm{CH} 3012$ Bern

Switzerland

Email: michael.gerfin@vwi.unibe.ch

\footnotetext{
* Michael Gerfin thanks the Swiss Science Foundation for financial support (Grant 610-062887). We thank the Federal Office of Statistics for permission to use the data (Swiss Health Survey) and Robert E. Leu for making the second wave of the data possible.
} 


\section{Introduction}

Health care expenditure increased considerably in Switzerland in the past years. Between 1998 and 2002 the increase amounted to 22\%. As a consequence the average premium for the compulsory basic health insurance increased by even $24 \%$ in the same period. Currently, the average premium amounts to about $10 \%$ of the median of equivalent household income. For many families paying the health care insurance premium has become a major financial burden. Not surprisingly, this development has put health care costs on top of the health and social policy agenda. One instrument thought to reduce the growth in health care expenditure is increased cost sharing because both insurance theory predicts and empirical evidence confirms that there is a negative correlation between the degree of cost sharing and expenditure. The Swiss health insurance law from 1996 provides the possibility of cost sharing in basic health insurance. The insured can choose between 5 possible deductible levels ranging from a minimum of $230 \mathrm{CHF}$ per year to a maximum of 1500 CHF. Choosing higher deductibles is combined with premium reductions. ${ }^{1}$

However, as is well known the negative correlation between the degree of cost sharing and the demand for health care can be due to two reasons: selectivity or moral hazard. If only healthy people who do not go to the doctor anyway choose high deductibles the observed negative correlation is mainly due to selectivity. In this case the size of the deductible has no impact on health care demand and health care costs. If on the other hand people become more cost-aware and change their health care demand behaviour there is a causal effect of the deductibles, thus reducing the moral hazard problem. Hence, in order to assess the cost-reducing potential of variable deductibles it is necessary to isolate the moral hazard (or treatment) effect.

The empirical evidence on the existence of moral hazard effects is mixed. Probably the most famous study is the RAND experiment (Manning et al., 1987). In this experiment people in several US states were randomly assigned to different insurance plans. These plans differed in the degree of cost sharing between patients and insurance company. The main result is that higher cost sharing reduces health care demand (measured by the number of doctor visits). Chiappori et al. (1998) analyse a natural experiment in France where health insurance companies varied in

1 Since January 2005 the maximum deductible is 2500 CHF. 
their reaction to a change in health insurance regulations. They do not find a significant effect of increased cost sharing on health care demand measured by the number of visits to general practitioners. On the other hand they estimate a significant effect on the number of home visits. Winkelmann (2004) analyses the effect of introducing a fee for drug prescriptions in Germany in the year 1997. Using panel data he estimates a significant reduction of the expected number of doctor visits due to this reform.

The empirical evidence for Switzerland is mixed as well. Gardiol et al (2003) and Werblow and Felder (2003) estimate a significant negative effect of the size of the deductible on health care costs. On the other hand, Schellhorn $(2001,2004)$ does not find any significant effects of the deductible on the number of doctor visits. The first two papers are based on data from a large insurance company, each covering only one canton ${ }^{2}$, whereas Schellhorn uses data from the Swiss Health Survey, which covers all of Switzerland.

One central problem of the existing empirical evidence for Switzerland is the underlying econometrics. The insurance company data used by Werblow and Felder (2003) are very informative regarding health care costs. However, there is a lack of variables that may help to solve the selection problem. Not surprisingly, the paper is not very clear about exclusion restrictions. The estimation method is a parametric selection model. Given these problems it is not clear whether the estimated parameters are unbiased estimates of the causal effect of deductibles on health care costs. Gardiol et al. (2003) use data from the same insurance company, but for a different canton. Their identification strategy is based on the assumption that there should be no moral hazard effect with respect to hospital expenditure (based on empirical evidence that the price elasticity of hospital care is close to zero). Under this assumption the estimated effect of the deductible on hospital costs is only due to selection. Given this estimate of the selection effect it is possible to decompose the estimated coefficients for outpatient care into the moral hazard and the selection effect. The estimation method is the parametric two-part model. Hence identification depends crucially both on the assumption regarding hospital expenditure and the correct specification of the statistical model. The papers by Schellhorn employ zero inflated count data regression models with endogenous regressors. In this case the

2 The data in Werblow and Felder are for the canton of Zurich, the data used by Gardiol et al. are for the canton of Vaud. 
exclusion restrictions are clearly explained. However, estimating the model requires strong distributional assumptions that may be violated by the data at hand.

For these reasons in this paper we estimate the effect of deductibles on the probability of going to the doctor with as little statistical assumptions as possible. We employ the method of nonparametric bounds on the treatment effect introduced by Manski (1990) and further developed among others by Manski (1997), Manski and Pepper (2000) and Shaik and Vytlacil (2005). Imposing several weak assumptions allows to bound the treatment effect away from zero. Our results indicate a negative effect of higher deductibles on the probability of going to a doctor.

This paper is organised as follows: section 2 gives a brief overview of the Swiss health insurance system. The data used in the empirical analysis are described in section 3. Section 4 presents the estimation strategy and section 5 discusses the estimation results. Section 6 concludes.

\section{The Swiss Health Insurance System}

Since the reform of the health insurance law in 1996 a basic health insurance is mandatory in Switzerland. This basic health insurance is provided by competing private insurers and covers a widely defined set of medical services. The health insurance premium is heavily regulated. Premiums for adults can vary between three regions in each canton but are not allowed to be related to risk-factors like age and sex or income. Every individual is insured with a separate contract. In 2002, the insured faced a choice between a minimal deductible of $230 \mathrm{CHF}$ and higher deductibles of 400,600, 1200 or 1500 CHF are optional. In order to make higher deductibles attractive they are combined with premium reductions. These reductions are regulated to be at most (8\%, 15\%, 30\% and 40\%) of the premium with the minimal deductible. Therefore, the potential savings from choosing a higher deductible vary substantially between cantons and regions. We will use this fact to generate an instrumental variable in our estimation strategy.

The insured have free choice between the insurance companies with open enrollment and can change their insurer and their deductible at the beginning of each calendar year. In 2002, the average monthly insurance premium for the contract with the minimal deductible was $245 \mathrm{CHF}$ and varied between $159 \mathrm{CHF}$ in the canton of Appenzell and $364 \mathrm{CHF}$ in the canton of Geneva. 
There is a large variance of premia within cantons as well. For example, the average premium in the canton of Zurich was 249 CHF in 2002; the lowest premium was 170 CHF and the largest premium was 390 CHF for virtually the same insurance. The main reason for this huge spread of the premia is that insurance companies face different risk and cost structures. To reduce the amount of risk selection induced by this type of premium regulation all insurance companies have to participate in a risk-adjustment pool. Depending on the risk structure of their enrollees insurers pay or receive contributions from this pool.

There is a co-payment rate of $10 \%$ when costs exceed the chosen deductible. There is a ceiling for co-payments of 600 SFr. per year irrespective of the chosen deductible. Health insurance premiums and out-of-pocket payments can eat up a substantial part of household income especially in larger families. To ease the financial hardship associated with per capita premiums, government provides means - tested subsidies to low income residents. In 2001 roughly one third of the insured were subsidized to some extent, and about $15 \%$ of all enrollee premium payments were paid for by the government. Subsidies are paid if premiums exceed a certain percentage of household income - usually $8 \%-10 \%$. The maximum amount paid is typically the mean of the premiums of all insurance companies in the canton.

Compulsory basic insurance covers outpatient care, including a wide variety of providers, hospital care $(100 \%$ coverage on the general ward of a public or publicly subsidized hospital in the enrollees' canton, except for a co-payment of CHF 10 per day), prescription drugs listed, preventive vaccinations, prescribed treatments in health resorts and alternative medicine. In addition, there are contributions to certain preventive tests, home care, glasses and medical devices as well as transportation and salvage expenses. In emergency cases up to twice the rate of the cantonal tariffs are paid for treatments abroad. Dental care, by contrast, is only covered in case of accident or severe dental problems. Compulsory insurance in the fee-for-service sector offers direct access and free choice of physician for outpatient care (general practitioners and specialists). Except for emergency cases hospitalisation requires referral by a physician. There is no choice of physician in the hospital. However, patients may freely choose among all hospitals which are included on the cantonal eligibility list.

Supplementary insurance covers additional treatments and check-ups, all drugs, extended home 
care, provides generally higher benefits and up to $100 \%$ universal coverage world wide. Most important it provides access to the private ward of all public and private hospitals in a one or twobedroom and free choice of physician in the hospital (medical or assistant medical director), depending on insurance package.

\section{Data}

The data come from the Swiss Health Survey (SHS) 2002 conducted by the Federal Bureau of Statistics. This cross section contains a large number of socioeconomic characteristics and information on health status and health care utilisation in the past 12 months. In this paper we use the subsample of those whose interview took place in the first quarter of 2002. These persons were interviewed a second time 6 months after the first interview. ${ }^{3}$ This second interview gives information on health care demand since the first interview and detailed information on health care insurance. Persons were asked to provide the name of their insurance company which allowed to compute the precise health insurance premium each person has to pay. Hence this subsample provides all the relevant information: deductible choice at the beginning of 2002 and health care demand in the first 6 months of 2002. In addition, there are several important variables to control for selection: age, gender, subjective health status, previous demand behaviour and risk factors like weight or smoking.

This subsample of the SHS 2002 contains 3623 observations. After deleting individuals younger than 19 (these face different regulations concerning deductibles) and individuals in alternative forms of insurance such as HMO and individuals with missing information on crucial variables the data contains 2860 observations. Table 1 provides descriptive statistics of some central variables separated by treatment status. In the remainder of this paper we consider three possible treatment states denoted by $D$, where

$D=\left\{\begin{array}{l}0 \text { if deductible }=230 \\ 1 \text { if deductible } \in\{400,600\} \\ 2 \text { if deductible } \in\{1200,1500\}\end{array}\right.$

This appears to be a natural combination of the 5 possible deductible levels. A little less than half

3 This additional interview was financed by the National Research Program 45, Future of the Social State. 
of the individuals have chosen the lowest deductible. Roughly one third opted for the medium deductible, and the remaining $18 \%$ decided to take the largest deductible. Not surprisingly, this group is on average younger and feels more healthy. Also not surprisingly men are more likely to opt for the largest deductible. There are also noticable differences with respect to education, income, previous health care demand, and the premium if the person had chosen the lowest deductible. This premium is computed using the information on the insurance company and the region of residence. The higher this hypothetical premium the higher is the saving potential for choosing higher deductibles. As discussed in section 2 there is a large variation in this imputed premium.

The outcome variable used in this paper is the indicator variable taking the value one if the person did see a doctor (either general practitioner or specialist) in the past 6 months. In the lowest deductible group $64 \%$ had at least one doctor visit, whereas only $40 \%$ in the highest deductible group went to the doctor. This finding corresponds to the well known negative correlation between the degree of cost sharing and health care utilisation. The same is true if we consider number of doctor visits. People in the lowest deductible group had on average 2.8 doctor visits compared to 1.3 visits of people in the highest deductible group. However, comparing the average number of doctor visits conditional on having seen a doctor reveals a much less pronounced difference across groups. This finding corresponds to the well known fact that the main choice people have is whether to see a doctor or not. Given they decided on a first consultation further doctor visits are to a large extent out of their control. For this reason we focus on the probability of going to a doctor as outcome variable. 
Table 1: Descriptive statistics

\begin{tabular}{|c|c|c|c|}
\hline Variable & Deductible:230 & Deductible:400/600 & Deductible:1200/1500 \\
\hline Female & 0.60 & 0.54 & 0.42 \\
\hline Age & 50 & 51 & 45 \\
\hline Education: high & 13 & 18 & 29 \\
\hline Education: average & 67 & 69 & 64 \\
\hline Education: low & 20 & 13 & 7 \\
\hline Smoke: yes & 32 & 30 & 31 \\
\hline Smoke: never & 46 & 49 & 46 \\
\hline Smoke: not any more & 22 & 21 & 23 \\
\hline Subjective health: excellent & 0.24 & 0.24 & 0.31 \\
\hline Subjective health: good & 0.58 & 0.61 & 0.61 \\
\hline Subjective health: not good & 0.18 & 0.15 & 0.08 \\
\hline Income & 2917 & 3157 & 3693 \\
\hline Premium (at lowest deductible) & 230 & 244 & 245 \\
\hline Doctor visit in 2001: 1 = yes & 0.78 & 0.74 & 0.58 \\
\hline Doctor visit in 2002: 1 = yes & 0.64 & 0.58 & 0.40 \\
\hline Number of doctor visits 2002 & 2.8 & 2.5 & 1.3 \\
\hline $\begin{array}{l}\text { Number of doctor visists } 2002 \\
\text { (excluding zeros) }\end{array}$ & 4.4 & 4.3 & 3.3 \\
\hline Number of observations & $1,362(47.6 \%)$ & $975(34.1 \%)$ & $523(18.3 \%)$ \\
\hline
\end{tabular}

Source: Swiss Health Survey 2002, own calculations

Table A.1 in the Appendix displays ordered probit estimates of the determinants of deductible choice. These estimates clearly indicate that deductible choice is strongly influenced by income, previous health care demand (measured by the number of doctor visits, a dummy for hospital stay and a dummy for exhaustion of deductible in the previous year), the hypothetical premium in case of the lowest deductible and regional differences.

The estimation strategy described below requires an instrumental variable. Possible instruments given the ordered probit results could be the regional indicators reflecting premium differences across cantons (as used in Schellhorn, 2001, 2004) or the imputed premium. The other significant variables in Table A.1 do not appear to be valid instruments because it is likely that they influence the outcome as well. We use the imputed premium as an instrument in our analysis. The reasoning is that the premium does not affect the costs of going to a doctor. Recall that the premium for basic insurance is independent of risk factors such as age or previous illnesses. Hence we believe that the imputed premium satisfies the weak assumptions required for an instrument as outlined below. In fact, these assumptions are weaker than those necessary for 
2SLS.

\section{Estimation strategy}

For each person $i$ we observe $\left(Y_{i}, D_{i}, X_{i}\right)$, where $Y_{\mathrm{i}}$ is the outcome variable, $D_{i}$ is the indicator of treatment, $D_{i} \in\{0,1,2\}$ as defined above, and $X_{i}$ is a vector of covariates.

To simplify notation the subscript $i$ will be dropped in the following. The observed outcome $Y$ is given by

(1) $\quad Y=1[D=t] Y_{t}, t=0,1,2$

where $Y_{\mathrm{t}}$ is the potential outcome if $D=t$ and $1[\cdot]$ is the indicator function equal to one if the expression in brackets is true.

The average treatment effect (ATE) is defined as

$$
A T E^{t, s}=E\left[Y_{t} \mid X\right]-E\left[Y_{s} \mid X\right]=E\left[Y_{t}-Y_{s} \mid X\right], t \neq s,
$$

where $A T E^{t, s}$ measures the effect of treatment $t$ relative to treatment $s$. In order to make the notation more compact we leave the conditioning on $X$ implicit in the following. As is well known ATE is not identified by the data. This can be easily shown by writing

$$
E\left[Y_{t}\right]=E\left[Y_{t} \mid D=t\right] P[D=t]+E\left[Y_{t} \mid D \neq t\right] P[D \neq t]
$$

The data identify $E\left[Y_{t} \mid D=t\right], P[D=t]$ and $P[D \neq t]$ but not $E\left[Y_{t} \mid D \neq t\right]$. The large and growing literature on estimating treatment effects is primarily concerned with solving this identification problem. There is a large variety of identification strategies: conditional independence assumptions, parametric selection models and estimators using instrumental variables. These assumptions can be very strong both in terms of functional form and distributional assumptions. Necessary exclusion restrictions for instrumental variables and selection models are often difficult to justify.

In this paper we analyse the effect of deductible choice with as few assumptions as possible. We 
employ the method of nonparametric bounds on treatment effects introduced by Manski (1990). Further developments have been made by Manski (1997), Manski and Pepper (2000), Heckman and Vytlacil (2001) and Vytlacil and Shaik (2004), among others. Applications are still relatively rare; examples include Pepper (2000), Ginther (2000), Gonzalez (2004) and Bhattacharya et al. (2005).

The main idea of estimating bounds can be illustrated as follows. Replace the unobserved $E\left[Y_{t} \mid D \neq t\right]$ in $E\left[Y_{t}\right]=E\left[Y_{t} \mid D=t\right] P[D=t]+E\left[Y_{t} \mid D \neq t\right] P[D \neq t]$ by its bounds $Y^{l}$ and $Y^{u}$, where $Y^{l}$ is the smallest value $Y$ can take and $Y^{u}$ is the largest value $Y$ can take. The lower bound for $E\left[Y_{t}\right]$ is then $B_{t}^{l}=E\left[Y_{t} \mid D=t\right] P[D=t]+Y^{l} P[D \neq t]$ and the corresponding upper bound for $E\left[Y_{t}\right]$ is $B_{t}^{u}=E\left[Y_{t} \mid D=t\right] P[D=t]+Y^{u} P[D \neq t]$

If $E\left[Y_{t}\right]$ is a probability we have: $Y^{l}=0 ; Y^{u}=1$. Hence the bounds for $E\left[Y_{t}\right]$ are

$$
E[Y \mid D=t] P[D=t] \leq E\left[Y_{t}\right] \leq E[Y \mid D=t] P[D=t]+P[D \neq t]
$$

or compactly

(6') $B_{t}^{l} \leq E\left[Y_{t}\right] \leq B_{t}^{u}$

with $B_{1}^{l}$ as lower bound and $B_{1}^{u}$ as upper bound of $E\left[Y_{t}\right]$. Now all terms in (6) are identified.

If $E\left[Y_{t}\right]$ is bounded then ATE is bounded as well. Assume that $t>s$. The lower bound of ATE is the difference between the lower bound of $E\left[Y_{t}\right]$ and the upper bound of $E\left[Y_{s}\right]$, and the upper bound is the difference between the upper bound of $E\left[Y_{t}\right]$ and the lower bound of $E\left[Y_{s}\right]$

$$
\left(B_{t}^{l}-B_{s}^{u}\right) \leq A T E^{t, s} \leq\left(B_{t}^{u}-B_{s}^{l}\right)
$$

These are the "worst-case bounds" of Manski (1990). In practice these bounds are too wide to be useful (and they always contain zero). The estimates in the present context are displayed in Appendix Table A.1. Therefore, Manski (1990, 1997) considers additional information that can be applied. He analyses the case where an instrument $Z$ is available that satisfies 
$E\left[Y_{t} \mid X, Z\right]=E\left[Y_{t} \mid X\right]$, i.e. $Z$ satisfies mean independence. In this case the bounds change to

$$
B_{t, I V}^{l}=\sup _{z}\{E[Y \mid D=t, Z=z] P[D=t, Z=z]\}
$$

and

$$
B_{t, N}^{u}=\inf _{z}\{E[Y \mid D=t, Z=z] P[D=t, Z=z]+P[D \neq t, Z=z]\}^{4}
$$

Interestingly, Heckman and Vytlacil (2001) show for the case of binary treatments that imposing a threshold crossing model structure on the treatment choice leads to formally identical bounds. Using the hypothetical premium if everybody chooses the lowest deductible as instrument still yields bounds that are much too wide to be helpful. Table A.1 in the Appendix displays the estimates.

Manski (1997) introduced the notion of monotone treatment response (MTR). MTR means that if $t>s$ than $Y_{t} \geq Y_{s}$ or $Y_{t} \leq Y_{s}$ : In our case MTR implies $Y_{t} \leq Y_{s}$, i.e. with increasing deductibles the probability of going to the doctor is not increasing. In other words assuming MTR implies that we know the sign of the treatment effect. This is a strong assumption but it appears reasonable in our case; the question is whether the treatment effect is zero or negative, which is compatible with the MTR assumption. ${ }^{5}$

Under MTR the bounds are modified as follows (ignoring the presence of instrument $Z$ for the moment). The first thing to note is that MTR implies that $E\left[Y_{t}\right] \leq E\left[Y_{s}\right]$. Then

$$
B_{t, M T R}^{l}=E[Y \mid D \geq t] P(D \geq t)
$$

and

$$
B_{t, M T R}^{u}=E[Y \mid D \leq t] P(D \leq t)+P[D>t]
$$

4 If $Z$ is discrete the supremum is the maximum and the infemum is the minimum over the possible values of $Z$.

5 There are of course applications where it is impossible to make the MTR assumption. For example, the sign of the effect of several active labour market programmes is not obvious a priori. Another example is the effect of catherization of emergency patients, which is analysed by Bhattacharya et al. (2005). 
Comparing (10) and (11) with (6) shows that under MTR not only observations with $D=t$ are informative for estimating the bounds of $E\left[Y_{t}\right]$ but all observations are informative. Because MTR implies that $E\left[Y_{t}\right] \leq E\left[Y_{s}\right]$ for $t>s$ all observations with treatment equal to or larger than $t$ can be used to compute the lower bound of $E\left[Y_{t}\right]$. Combining MTR with the IV $Z$ is straightforward. We have to compute (10) and (11) conditional on $Z$ and take the supremum and infemum, respectively, with respect to $Z$.

Interestingly, there is a tight link to the bounds introduced by Shaikh and Vytlacil (2005) who assume that both treatment choice and outcome are binary and generated by a nonparametric threshold crossing model. These assumptions are stronger than those imposed by Manski but it is not necessary to know the sign of the treatment effect a priori. It can be shown that the Shaikh and Vytlacil bounds are identical to the MTR + IV bounds if the assumed sign of the treatment effect corresponds to the sign identified by the Shaikh and Vytlacil assumptions.

Manski and Pepper (2000) introduce the assumption of monotone treatment selection (MTS). Formally, MTS can be expressed as $E\left[Y_{t} \mid D=t\right) \leq E\left[Y_{t} \mid D=s\right], s<t .{ }^{6}$ In words MTS implies that persons who chose higher deductibles have weakly lower mean response functions. In our case this means that people who choose the highest deductible have a lower probability of seeing a doctor than those who choose a low deductible would have if they had chosen the highest deductible. In other words people who choose lower deductibles have observed and unobserved characteristics that make them more likely to see a doctor even if they had the highest deductible. If we are willing to make this assumption the bounds for $E\left[Y_{t}\right]$ can be written as (again ignoring the instrument $Z$ for the moment)

$$
B_{t, M T S}^{l}=E[Y \mid D=t] P[D \leq t]
$$

and

${ }^{6}$ Or $E\left[Y_{t} \mid D=t\right) \geq E\left[Y_{t} \mid D=s\right], s<t$, depending whether we assume that the treatment effect is negative or positive. 


$$
B_{t, M T S}^{u}=E[Y \mid D=t] P[D \geq t]+P[D<t]^{7}
$$

These bounds follow straightforwardly from the MTS assumption. The lower bound for $E\left[Y_{t}\right]$ is $E[Y \mid D=t]$ times the probability $P[D \leq t]$ because by assumption for each $D<t$ it must be true that $E\left[Y_{t}\right]$ is at most as large as $E[Y \mid D=t]$. Hence compared to the worst case bounds the lower bound is increased by $E[Y \mid D=t] P[D<t]$. The upper bound can be expained by similar arguments. It is easy to show that the binary treatment case MTS implies that the treatment effect cannot be larger in absolute terms than the total absolute difference in the outcome variable. Hence MTS implies that treatment selection is rational.

It is possible to combine the MTS assumption with the mean independence assumption for the instrument $Z$ and with the MTR assumption. Combining MTR and MTS yields the following bounds for $E\left[Y_{t}\right]$ (the derivation is straightforward, see Manski and Pepper, 2000)

$$
B_{t, M T R+M T S}^{l}=\sum_{u>t} E[Y \mid D=u] P[D=u]+E[Y \mid D=t] P[D \leq t]
$$

and

$$
B_{t, M T R+M I S}^{u}=\sum_{u<t} E[Y \mid D=u] P[D=u]+E[Y \mid D=t] P[D \geq t]
$$

The first part in (14) and (15) comes from the MTR assumption and the second part from the MTS assumption. Again incorporating the instrument $Z$ is straightforward. In this case the lower bound is the maximum of (14) conditional on $Z$ over all values of $Z$ and the upper bound is the minimum of (15) conditional on $Z$ over all values of $Z$. An interesting feature of the bounds in (14) and (15) is that they do no longer depend on the bounds $Y^{l}$ and $Y^{u}$.

There is again a tight link to the bounds considered by Bhattacharya et al. (2005). They combine the Shaikh and Vytlacil bounds (which are closely related to the MTR+IV assumption by Manski) with an assumption of positive quadrant dependence. Positive quadrant dependence corresponds to MTS in the sense that people with unobserved characteristics that make them

7 See Manski and Pepper (2000) for the derivation. 
more likely to choose the treatment also have unobserved characteristics that make them more likely to have a positive outcome, i.e. that they have a weakly higher mean response function. ${ }^{8}$ In other words, this assumption implies that there is selection on unobservables that are correlated with the unobservables in the outcome equation.

Summarizing, we make three additional assumptions (and combinations thereof) in order to tighten the no-assumption bounds on the treatment effect of deductibles. Of these assumptions the mean independence assumption for the instrument $Z$ is weak and the MTR and the MTS assumptions appear to be reasonable in the present context.

\section{Results}

This section presents the main results of the described bounding analysis. A full set of results is presented in the Appendix. Not surprisingly it turns out that most of the bounding strategies yield bounds that are too wide to be informative. This is especially true for the worst case bounds, the IV bounds but also for the MTR and the MTS bounds. Table 2 displays the estimated bounds under the MTR+IV and under the MTR+MTS+IV assumptions. If one is willing to accept the MTR+IV assumptions the results indicate a negative treatment effect comparing the highest deductible with the lowest deductible $\left(A T E^{0,2}\right)$. However, the bounds are still relatively wide (between -.68 and -.07). The bounds for the other two tratment effects $\left(A T E^{0,1}\right.$ and $A T E^{1,2}$ ) include zero.

Table 2: Estimated Bounds of ATE under MTR $+I V$ and $M T R+M T S+I V, Z=$ Premium

\begin{tabular}{|c|c|c|c|c|c|c|c|c|c|c|c|}
\hline \multicolumn{6}{|c|}{ MTR + IV } & \multicolumn{6}{|c|}{ MTR + MTS + IV } \\
\hline \multicolumn{2}{|c|}{ ATE 0,1} & \multicolumn{2}{|c|}{ ATE $^{1,2}$} & \multicolumn{2}{|c|}{ ATE 0,2} & \multicolumn{2}{|c|}{ ATE 0,1} & \multicolumn{2}{|c|}{$A T E^{1,2}$} & \multicolumn{2}{|c|}{ ATE 0,2} \\
\hline$B^{\prime}$ & $B^{u}$ & $B^{\prime}$ & $B^{u}$ & $B^{\prime}$ & $B^{u}$ & $B^{\prime}$ & $B^{u}$ & $B^{\prime}$ & $B^{u}$ & $B^{\prime}$ & $B^{u}$ \\
\hline-0.44 & 0 & -0.54 & 0 & -0.68 & -0.07 & -0.05 & 0 & -0.09 & -0.04 & -0.11 & -0.07 \\
\hline
\end{tabular}

Adding the MTS assumption tightens the bounds considerably. Now both $A T E^{1,2}$ and $A T E^{0,2}$ are bounded away from zero. Under these assumptions $A T E^{0,2}$ is bounded between -.11 and -.07.

8 Recall that the Shaikh and Vytlacil bounds are only applicable to binary treatments and outcomes. 
Given that the total difference between the outcomes of treatment 0 and treament 2 is -.24 (.40 .64; see Table 1) we conclude from this result that the treatment effect (the moral hazard effect) is about one third of the total difference.

So far we have ignored the fact that the bounds are estimated. The upper part of Table 3 repeats the estimated bounds under the MTR+MTS+IV assumption and displays bootstrapped confidence intervals for these estimates. The first thing to note is that the upper bound for $A T E^{1,2}$ is not significantly different from zero. However, in the case of $A T E^{0,2}$ the estimated confidence bands do not include zero.

Table 3: Estimated Bounds of ATE and Confidence Intervals under MTR $+M T S+I V, Z=$ Premium and Estimated Treatment Effects based on Propensity Score Matching

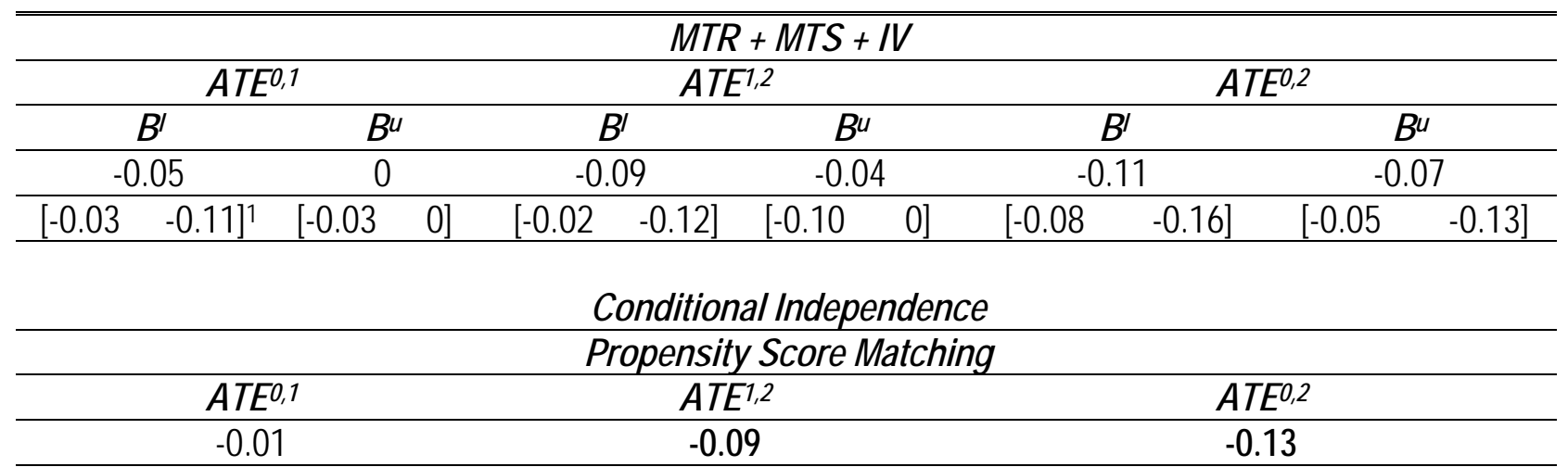

Source: Swiss Health Survey 2002, own calculations

1 The figures in brackets are 95\% confidence bands for the estimated bounds based on 1000 bootstrap replications

Propensity scores are computed according to the ordered probit results displayed in Table A.1.

Matching is done as nearest neighbor matching;, standard errors are computed according to the bias-adjusted method proposed by Abadie und Imbens (2004). Italic print indicates significance on the $10 \%$ level, bold print indicates significance on the $5 \%$ level.

The lower part of Table 3 presents estimates of the treatment effect based on the popular propensity score matching technique. Propensity score matching is based on the conditional independence assumption, i.e. conditional on all observable factors $X$ influencing both treatment choice and outcomes treatment and potential outcomes are independent. Hence conditional independence is often called selection on observables. Instead of conditioning on $X$ Rosenbaum and Rubin (1983) have shown that it is sufficient to condition on the propensity score, i.e. the probability of choosing treatment $t$ given $X$. Formally, the propensity score in the present context is $P(D=t \mid X)$ obtained from the ordered probit estimates (see Appendix Table A.1). The 
matching estimates displayed in Table 3 are computed using nearest neighbour matching, i.e. to each person in treatment group $t$ we match that observation from treatment group $s$ which is closest in terms of the propensity score.

The matching estimate of $A T E^{1,2}$ is -0.09 and is statistically significantly different from zero. ${ }^{9}$

The corresponding estimate of $A T E^{0,2}$ is -0.13 and also statistically significantly different from zero. Interestingly, in both cases these estimates are very close to the bounds estimated under IV+MTR+MTS and lie within the confidence bands of these bounds. This finding suggests that the conditional independence assumption underlying the matching estimates appears to be valid in the present context. The main reason for this is that we are able to control for past realisations of the outcome variable which should take account of unobserved characteristics influencing the probability of seeing a doctor.

\section{Conclusions}

There is an ongoing debate in health economics whether cost sharing in health insurance changes the behaviour of patients. The well documented negative correlation between the degree of cost sharing and health care costs can be attributed to changes in behaviour (reduction of moral hazard) or selection (more healthy people select higher cost sharing). Previous empirical evidence for Switzerland, which was obtained based on strong identification assumptions, is mixed. In this paper we estimate the effect of deductibles with as few statistical assumptions as possible. We employ the nonparametric bounding techniques introduced by Manski (1990) and further developed by Manski (1997), Manski and Pepper (2000) and Shaikh and Vytlacil (2005), among others. Treatment is ordered in our application. We consider three possible treatment states: low deductible, medium deductible and high deductible. The outcome variable is the probability of going to the doctor.

Our empirical analysis shows that we need some assumptions to tighten the bounds; the noassumption bounds are too wide to be useful. We consider three further assumptions: a mean independence assumption for an instrument, the assumption that treatment response is monotone (i.e. we assume the sign of the treatment effect to be known), and the assumption that treatment selection is monotone (i.e. the mean response function differs across treatment choices). Under 
the first two assumptions we estimate bounds for the treatment effect of the high deductible compared to the low deductible that are below zero. Hence given these two assumptions we conclude that there is a negative treatment effect (i.e. there is a change in behaviour). This finding is in contrast to previous empirical analyses based on the same data. Adding the third assumption allows to tighten the bounds further to an interval of -0.04 (the estimated bounds are $-0.11$ and $-0.07)$.

The research presented in this paper can be extended in several directions. So far, we did not control for covariates. It is possible that the estimated bounds differ for different subgroups. Methodologically, we plan to apply to bounding techniques proposed by Shaikh and Vytlacil (2005) and Bhattacharya et al. (2005). To do so, we need to concentrate on binary treatments (as opposed to three treatments in the present application). Given that there appears to be mainly an effect of the high deductible compared to the low deductible the reduction to a binary treatment appears to be meaningful. Finally, we can attempt to expand the Shaikh and Vytlacil analysis to ordered treatments.

9 Standard errors are computed according to the bias-adjusted method proposed by Abadie und Imbens (2004) 


\section{References}

Abadie, A. and G. Imbens (2004), "Large Sample Properties of Matching Estimators for Average Treatment Effects”, Econometrica, forthcoming.

Bhattacharya, J., A. Shaikh, and E. Vytlacil (2005), "Treatment Effect Bounds: An application to Swan-Ganz Catherization”, working paper, Department of Economics, University of Stanford.

Bundesamt für Sozialversicherung BSV (Hrsg., 2002): Statistik über die Krankenversicherung 2001, Bern.

Chiappori, P.-A., F. Durand, and P.-Y. Geoffard (1998), "Moral hazard and the demand for physician services : First lessons from a french natural experiment”, European Economic Review, 42, 499-511.

Gardiol, L., P. Geoffard and C, Grandchamp (2003): "Separating Selection and Incentive Effects: An Econometric study of Swiss insurance claims data”, Working Paper 2003-27, DELTA, Paris.

Ginther, D.K. (2000), „Alternative Estimates of the Effect of Schooling on earnings“, Review of Economics and Statistics, 82, 103-116.

Gonzalez, L. (2004), "Nonparametric Bounds on the Returns to Language Skills", Journal of Applied Econometrics, forthcoming.

Heckman, J. and E. Vytlacil (2001), "Instrumental variables, selection models, and tight bounds on the average treatment effect”, in: Lechner, M. and F. Pfeiffer (eds), Econometric Evaluation of Active Labor Market Policies in Europe, Physica Verlag, Heidelberg and New York.

Manning, W.G., J.P. Newhouse, N. Duan, E.B. Keeler, A. Leibowitz, and M.S. Marquis (1987), "Health Insurance and the Demand for Medical Care: Evidence from a Randomized Experiment”, American Economic Review, 77, 251-277.

Manski, C.F. (1990), "Nonparametric Bounds on treatment effects", American Economic Review, Papers and Proceedings, 80:319-323.

Manski, C.F. (1994), “The selection problem”, in: Manski, C.F. and D. McFadden (eds), Advances in Econometrics: Sixth World Congress, Cambidge University Press, Cambridge

Manski, C.F: (1997), “Monotone Treatment Response,” Econometrica, 65, 1311-1334.

Manski, C.F. and J. Pepper (2000), "Monotone instrumental variables: with an application to the returns to schooling”, Econometrica 68, 997-1010.

Pepper, J. (2000), „The Intergenerational Transmission of welfare receipt: A Nonparametric Bounds Analysis“, Review of Economics and Statistics, 82, 472-488.

Rosenbaum, P.R. and Rubin, D.B. (1983): "The Central Role of the Propensity Score in Observational Studies for Causal Effects”, Biometrika 70: 1, 41-55.

Rosenbaum, P.R. and Rubin, D.B. (1985): "Constructing a Control Group Using Multivariate Matched Sampling Methods that Incorporate the Propensity Score”, The American Statistician 39: 33-38.

Schellhorn, M. (2001): “The Effect of Variable Health Insurance Deductibles on the Demand for Physician Visits”, Health Economics 10: 441-456.

Schellhorn, M. (2004), "Wählbare Selbstbehalte in der Krankenversicherung in der Schweiz: Nachfragesteuerung oder Selektion?, Diskussionsschriften des Volkswirtschaftlichen Instituts der Universität Bern 04/02.

Shaikh, A. and E. Vytlacil (2005): "Threshold Crossing Models and Bounds on Treatment Effects: A nonparametric analysis, working paper, Department of Economics, University of Stanford.

Werblow, A. and S. Felder (2003): "Der Einfluss von freiwilligen Selbstbehalten in der Gesetzlichen Krankenversicherung. Evidenz aus der Schweiz“, Schmollers Jahrbuch 123: 235-264.

Winkelmann, R. (2004), "Health Care Reform and the Number of Doctor Visits - An Econometric Analysis", Journal of Applied Econometrics, 19, 455-472

Zweifel, P. und W. G. Manning (2000), "Moral Hazard and Consumer Incentives in Health Care”, in: A.J. Culyer and J.P Newhouse (eds.), Handbook of Health Economics 1A: 409-459. 


\section{APPENDIX}

Table A.1: Ordered Probit Estimates of Deductible Choice

\begin{tabular}{|c|c|c|}
\hline Variable & coefficient & t-value \\
\hline male $x$ age $15-34$ & 0.526 & 3.575 \\
\hline male $x$ age $35-44$ & 0.561 & 4.096 \\
\hline male $x$ age $45-64$ & 0.242 & 1.856 \\
\hline male $x$ age $65-74$ & -0.037 & -0.255 \\
\hline female $x$ age15-34 & 0.155 & 1.046 \\
\hline female age $35-44$ & 0.201 & 1.455 \\
\hline female $x$ age $45-64$ & 0.085 & 0.665 \\
\hline female $x$ age $65-74$ & 0.035 & 0.243 \\
\hline female $x$ age $75+$ & -0.240 & -1.458 \\
\hline secundary education & 0.183 & 2.653 \\
\hline tertiary education & 0.427 & 4.965 \\
\hline unemployed & -0.206 & -0.941 \\
\hline log household income & 0.254 & 6.381 \\
\hline Swiss & 0.224 & 3.061 \\
\hline Single & -0.096 & -1.064 \\
\hline Married & 0.097 & 1.254 \\
\hline Widow & 0.001 & 0.012 \\
\hline nonsmoker & 0.033 & 0.639 \\
\hline heavy smoker & -0.170 & -2.696 \\
\hline underweight & 0.055 & 0.726 \\
\hline overweight & -0.040 & -0.795 \\
\hline region lemanique & 0.248 & 2.578 \\
\hline region espace mittelland & 0.341 & 3.926 \\
\hline region north-west & 0.179 & 1.923 \\
\hline region east & 0.094 & 0.916 \\
\hline region central & 0.250 & 2.500 \\
\hline region south (ticino) & 0.660 & 5.088 \\
\hline subjective health excelllent & -0.188 & -1.161 \\
\hline subjective health good & -0.117 & -0.798 \\
\hline subjective health average & -0.136 & -0.912 \\
\hline Premium with lowest deductible & 0.350 & 6.568 \\
\hline Hospital visit last year & -0.023 & -0.330 \\
\hline number of doctor visits last year & -0.010 & -2.699 \\
\hline chronic disease & -0.110 & -1.958 \\
\hline pregnant & 0.216 & 1.522 \\
\hline subjective health worse than in previous year & 0.070 & 1.912 \\
\hline used up deductible in previous year & -0.384 & -7.645 \\
\hline Distance to nearest physician & -0.001 & -0.286 \\
\hline cutoff 1 & 3.486 & 6.439 \\
\hline cutoff 2 & 4.553 & 9.049 \\
\hline Number of observations & 2860 & \\
\hline Log Likelihood & -2732.33 & \\
\hline
\end{tabular}


Table A.2: Estimated bounds for ATE under different assumptions

\begin{tabular}{|c|c|c|c|c|c|}
\hline \multicolumn{2}{|c|}{$\overline{A T E^{0,1}}$} & \multicolumn{2}{|c|}{$A T E^{1,2}$} & \multicolumn{2}{|c|}{$A T E^{0,2}$} \\
\hline$B^{\prime}$ & $B^{u}$ & $B^{\prime}$ & $B^{u}$ & $B^{\prime}$ & $B^{u}$ \\
\hline \multicolumn{6}{|c|}{ Worst case } \\
\hline-0.63 & 0.55 & -0.78 & 0.69 & -0.75 & 0.59 \\
\hline \multicolumn{6}{|c|}{ IV } \\
\hline-0.53 & 0.50 & -0.74 & 0.61 & -0.68 & 0.52 \\
\hline \multicolumn{6}{|c|}{ MTR } \\
\hline-0.56 & 0 & -0.61 & 0 & -0.75 & 0 \\
\hline \multicolumn{6}{|c|}{ MTS } \\
\hline-0.16 & 0.48 & -0.38 & 0.42 & -0.24 & 0.59 \\
\hline \multicolumn{6}{|c|}{ MTR + MTS } \\
\hline-0.09 & 0 & -0.21 & 0 & -0.24 & 0 \\
\hline \multicolumn{6}{|c|}{$M T R+I V$} \\
\hline-0.44 & 0 & -0.54 & 0 & -0.68 & -0.07 \\
\hline \multicolumn{6}{|c|}{$M T S+I V$} \\
\hline-0.08 & 0.40 & -0.26 & 0.36 & -0.11 & 0.52 \\
\hline \multicolumn{6}{|c|}{$M T R+M T S+I V$} \\
\hline-0.05 & 0 & -0.09 & -0.04 & -0.11 & -0.07 \\
\hline
\end{tabular}

Source: Swiss Health Survey 2002, own calculations 